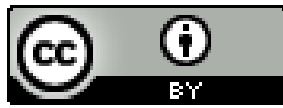

\title{
A HERANÇA DO COMÉRCIO DA ÁFRICA PRÉ-COLONIAL NAS PRÁTICAS COMERCIAIS EM SALVADOR E NO RIO DE
}

\author{
JANEIRO: CONTINUIDADES E RUPTURAS
}

Vitor Henrique Guimarães Lima ${ }^{1}$

Resumo: $\mathrm{O}$ ambiente de mercado e as práticas comerciais sempre tiveram importância social muito além da esfera financeira para os povos africanos sudaneses e bantos, dois dos principais povos que sofreram com o rapto de parte da população para o tráfico negreiro nas Américas. Quando chegaram nas cidades brasileiras, principalmente em Salvador e no Rio de Janeiro, os indivíduos acabaram por reproduzir algumas dessas práticas socioculturais. É possível observar continuidades e rupturas quanto ao significado cultural dessas práticas e do ambiente comercial aqui no Brasil em relação ao que se observava no continente africano, seja por imposição hegemônica, seja por adaptação e sobrevivência. Neste trabalho, procurarei identificar algumas possibilidades de continuidades e rupturas, tendo atenção às diferentes relevâncias do comércio e dos mercados para os povos diaspóricos que foram trazidos para as cidades brasileiras.

Palavras-Chave: Práticas comerciais; Sociabilidade negra; Cultura urbana; Cosmovisão.

\section{THE HERITAGE FROM PRE-COLONIAL AFRICA ON COMERCIAL PRACTICES AT SALVADOR AND RIO DE JANEIRO: CONTINUITIES AND RUPTURES}

\begin{abstract}
The market environment and the comercial practices always had great social importance, far beyond the financial meaning, for bantu and sudanese folks, two of the cultures wich suffered the most with the rapt of its population for the black traffic transitions made by Europeans between African continent and the Americas. When brought to Brazilian cities, mostly Salvador and Rio de Janeiro, African individuals came to reproduce some of those sociocultural practices. It's possible to observe continuities and ruptures when we look at the cultural meaning of these practices and at the commercial environments in Brazil in comparison with the same factors in pre-colonial Africa, may it be for hegemonic imposition or by adaptation or surviving. In this work, I'll seek to identify some possibilities of these continuities and ruptures, always paying attention to the different relevances of the markets and commerce to diasporics people brought to Brazilian cities.
\end{abstract}

1 Bacharel em Geografia (UFRJ), mestrando em Cultura e Territorialidade (UFF). E-mail:
vitorhgmrs@gmail.com 
Key-words: Comercial practices; black sociabilites

\section{EL PATRIMONIO DEL COMERCIO DE ÁFRICA DE PRÁCTICAS COMERCIALES EN SALVADOR Y RÍO DE JANEIRO: CONTINUIDADES Y RUPTURAS}

Resumen: El entorno de mercado y las prácticas comerciales siempre han tenido una importancia social mucho más allá de la esfera financiera para los sudaneses y bantús africanos, dos de los principales pueblos que sufrieron con el secuestro de parte de la población para el tráfico de esclavisados en las Américas. Cuando llegaron a las ciudades brasileñas, principalmente a Salvador y Río de Janeiro, los individuos terminaron reproduciendo algunas de estas prácticas socioculturales. Es posible observar continuidades y rupturas con respecto al significado cultural de estas prácticas y el entorno comercial aquí en Brasil en relación con lo que se observó en el continente africano, sea por imposición hegemónica, sea por adaptación y supervivencia. En este trabajo, trataré de identificar algunas posibilidades de continuidad y ruptura, con atención a las diferentes relevancias del comercio y los mercados para los pueblos de la diáspora que fueron llevados a las ciudades brasileñas.

Palabras-clave: prácticas comerciales; Sociabilidad negra; Cultura urbana; Cosmovisión.

\section{LE PATRIMOINE DU COMMERCE AFRICAIN DES PRATIQUES COMMERCIALES À SALVADOR ET RIO DE JANEIRO: CONTINUITÉS ET RUPTURES}

Résumé: L'environnement du marché et les pratiques commerciales ont toujours eu une importance sociale bien au-delà de la sphère financière pour les peuples soudanais et bantous d'Afrique, deux des principaux peuples qui ont souffert de l'enlèvement d'une partie de la population pour le trafic d'esclaves aux Amériques. Lorsqu'ils sont arrivés dans les villes brésiliennes, principalement à Salvador et à Rio de Janeiro, les individus ont fini par reproduire certaines de ces pratiques socioculturelles. Il est possible d'observer des continuités et des ruptures concernant la signification culturelle de ces pratiques et de l'environnement commercial ici au Brésil par rapport à ce qui a été observé sur le continent africain, soit par imposition hégémonique, soit par adaptation et survie. Dans ce travail, je vais essayer d'identifier certaines possibilités de continuités et de ruptures, en prêtant attention aux pertinences différentes du commerce et des marchés pour les peuples diasporiques qui ont été amenés dans les villes brésiliennes.

Mots-clés: Pratiques commerciales; Sociabilité noire; Culture urbaine; Cosmovision.

\section{INTRODUÇÃO}

A cosmovisão é um elemento fundamental para entendermos as tensões sociais. Sire (2009) define cosmovisão como 
"um comprometimento, uma orientação fundamental do coração, que pode ser expressa como uma história ou um conjunto de pressuposições (hipóteses que podem ser total ou parcialmente verdadeiras ou totalmente falsas), que detemos (consciente ou subconscientemente, consistente ou inconsistentemente) sobre a constituição básica da realidade e que fornece o alicerce sobre o qual vivemos, movemos e possuímos nosso ser" (p. 16).

A tendência no mundo contemporâneo é de acreditar que as cosmovisões tendem mais à homogeneidade (como possível produto da globalização) e que quando diferem são por motivos espirituais ou religiosos, entretanto, para muito além dessas motivações, nota-se que há pressupostos mais vigentes no cotidiano que outros. É possível ao menos levantar a hipótese de que a sensação de homogeneidade de cosmovisões é fruto da reprodução de práticas e de privilégios sociais de grupos politicamente hegemônicos (e não necessariamente da maioria populacional) que, por suas vezes, estão calcados no exercício sistêmico de violências de diferentes naturezas sobre os grupos sociais minoritários ao longo da história.

Numa sociedade escravocrata, contudo, as fronteiras entre essas cosmovisões estavam muito mais claras. Ainda que não fosse exatamente uma preocupação por parte das elites sociais definir essas diferenças - a preocupação era, essencialmente, dominar e controlar socialmente os indivíduos negros, estivessem eles livres, libertos ou ainda escravizados -, as tensões étnico-raciais se manifestavam diariamente no espaço urbano brasileiro, como será mostrado mais adiante neste trabalho.

Mbembe (2018), ao falar sobre o conceito de necropolítica, diz que "a expressão máxima da soberania é a produção de normas gerais por um corpo [povo] composto por homens e mulheres livres e iguais" (p. 9). Esse grupo representaria aqueles cuja razão pauta o fazer político. O autor completa: “a política, portanto, é definida duplamente: um projeto de autonomia e a realização de acordo em uma coletividade mediante comunicação e reconhecimento" (p. 9; grifos meus). Ora, se é necessário se comunicar e reconhecer o outro para fazer política e construir normas gerais, e numa sociedade escravocrata a população negra não está inserida nos grupos sociais que produzem essas normas gerais por não terem voz e não serem reconhecidos (nem mesmo sua dignidade, visto que não são livres) - então a população negra está distante do fazer político.

A narrativa do senso comum (construída pela hegemonia através da supressão das narrativas periféricas) põe a figura do negro (em condição livre ou de escravizado) como 
agente passivo na história brasileira, principalmente durante o período escravocrata, salvas algumas exceções espacial e cronologicamente distantes - como exemplos mais famosos, temos o Quilombo dos Palmares durante o século XVII, em Alagoas; a Revolta dos Malês na Bahia, em 1835; e a Guerra dos Canudos, que durou de 1896 a 1897, no sertão baiano. Entretanto, a comunidade negra teve grande relevância não só em amplas frentes de luta e resistência, como também na composição sociocultural brasileira e na produção do espaço urbano - e de uma maneira ativa.

Um dos desafios para aqueles que estudam influência de negros africanos e crioulos (negros nascidos no Brasil) no país têm é entender como cada nação africana imprimiu seus traços culturais na sociedade brasileira. Aqui se entende uma "nação" ou uma "nacionalidade" como uma ideia duplamente instável, visto que, por um lado, era uma atribuição muitas vezes feita por traficantes de escravizados, como aponta Soares (2001) e a partir deles reproduzida pela classe senhorial e pela imprensa; por outro, uma "nacionalidade" poderia ser forjada nas travessias atlânticas pelos próprios negros como estratégia de resistência através do estabelecimento de laços afetivos e alianças sociais. Um dos esforços deste trabalho é tentar identificar algumas continuidades e rupturas dos simbolismos em torno dos ambientes de mercado e da prática comercial para os africanos, comparando as dinâmicas sociais entre o que ocorria no continente africano antes do processo de colonização africana e o que se dava em solo brasileiro, com foco nas cidades de Salvador e Rio de Janeiro a partir do século XIX.

É comum encontrar em estudos acadêmicos, e isso é observado por Gomes (2014), a relevância da religião e do gênero na formação sociocultural afro-brasileira - dois elementos que constituem fundamentalmente as cosmovisões e que se manifestam nas práticas e nas relações sociais. Por isso, outro esforço deste trabalho é mirar no significado do comércio de rua e dos mercados na cosmovisão desses povos africanos a partir dos pontos de vista de gênero e das crenças.

O destaque dado neste trabalho aos lugares de mercado se dá devido à sua relevância simbólica para as diversas "nações" africanas, algo que vai além de um sentido mais econômico, como observado na cosmovisão europeia. Tanto Hymer (1970), quanto Waldman (2016) e Apter (2013) apontam uma dimensão sociocultural do mercado que supera suaa dimensão econômica, ou seja, o mercado como simples lugar de trocas comerciais e relações econômicas. Havia, de um lado, a forte função social dos mercados

Revista da ABPN • v. 12, n. Ed. Especial - Caderno Temático: “Geografias Negras” • abril de 2020, p. 175-199 
como um lugar para troca de ideias e de informações e, em outra parte, sua função econômica, de fato. Nas sociedades ganesas (antes de serem colonizadas), por exemplo, as sociedades eram majoritariamente autossuficientes; portanto, as conexões e relações nos mercados se realizavam por motivos muito mais políticos e socioculturais do que por razões econômicas. Portanto, este trabalho procura também sublinhar as atividades comerciais e os ambientes de mercado como um importante traço sociocultural da população negra nos espaços urbanos brasileiros.

Além disso, o conceito de "etnocídio" a partir do discutido por Correia (2011) e a ideia de identidades diaspóricas a partir de Hall (2016) também são trazidos para debate.

\section{MINAS E BANTOS: DESLOCAMENTO DEMOGRÁFICO E CULTURAL NOS FLUXOS DO TRÁFICO NEGREIRO}

Dentre os eixos de comércio de escravizados pelo Atlântico, Alencastro (2018) dá destaque a dois: um entre a África Ocidental (portos pertencentes ao Golfo da Guiné) e o Nordeste brasileiro (principalmente os portos de Recife e de Salvador), e outro entre os portos da atual Angola e o porto do Rio de Janeiro. Do primeiro fluxo, eram capturados africanos dos povos sudaneses, principalmente, os jeje, os iorubás e os hauçás. Do segundo fluxo, foi o povo banto o que sofreu com a captura. Os dois fluxos podem ser observados no mapa da Figura 1, junto a um terceiro fluxo que é de Moçambique para o porto do Rio de Janeiro.

$\mathrm{O}$ autor estima que, dentre os africanos que chegaram vivos ao Brasil entre 1550 e 1850 (fim legal do tráfico de escravizados para o Brasil), 75\% (cerca de 3.656 .000 de africanos) vinham da África Centro-Ocidental, 20,5\% (cerca de 999.600 de africanos) vinham da África Central e os 4,5\% restantes vinham da África Centro-Oriental (principalmente da região onde hoje é o Moçambique). O Brasil foi o território onde mais negros africanos desembarcaram como decorrência do tráfico negreiro.

Parés (2018) reforça Alencastro ao dizer a região que mais sofreu com a captura de negros foi a chamada Costa da Mina, faixa que se estende a leste do castelo de São Jorge da Mina (na atual Gana) até o Rio Lagos (na atual Nigéria). O autor estima também $75 \%$ dos africanos ocidentais trazidos para o Brasil desembarcaram na Bahia. De uma

Revista da ABPN • v. 12, n. Ed. Especial - Caderno Temático: “Geografias Negras”• abril de 2020, p. 175-199 
maneira geral, como aponta Soares (2001), havia uma diversidade linguística na região, mas também havia semelhança no universo mítico-religioso entre os povos que sofreram com a captura de parte de sua população, o que contribuiu para que novas identidades fossem forjadas como estratégia de sobrevivência e articulação interna. Devido às extensas bacias hidrográficas, como a do Rio Gâmbia e as dos rios Senegal, Volta e Níger, houve um forte processo de interiorização da captura de africanos, o que contribuiu para a captura de negros de "nações" mais interioranas.

Através dos relatos de marinheiros e de escravizados na travessia (Gomes, 2013) e pelas denúncias retratadas pelas imprensas baiana e carioca, os povos da África Ocidental mais citados como originários de negros trazidos para o Brasil, são os hauçás (ocupavam o Sudão Central, na região norte da Nigéria e acima, distantes do litoral e com forte influência da cultura islâmica), os iorubás (ocupavam o litoral nigeriano; também chamados de nagôs) e os jejes - estes dois últimos apontados Parés (2018) como um bom exemplo de grupos que enquanto no continente africano se mostravam como diferentes, mas que após a diáspora se organizaram para elaborar estratégias para sobreviver. Mais tarde, no Rio de Janeiro, quando os africanos chegam à cidade, todas as nacionalidades de africanos ocidentais ficam sob o guarda-chuva do termo "negros minas" - que remete à Costa da Mina.

Do Sudão Central, estima-se que entre 75 e 124 mil dos cativos capturados no Sudão Central entre 1804 e 1850 foram desembarcados em Salvador. A partir da análise de Lovejoy (2000), feita a partir da leitura do estudo da biografia de 117 indivíduos originários do Sudão Central, pode-se dizer que isso se torna relevante ao pensar que em 1804 ocorreu a jhad (Guerra Santa) muçulmana na região, o que gerou forte impacto nas relações étnico-raciais (interações e relações de domínio) dos africanos tanto ainda no continente africano quanto em solo brasileiro. Mas é necessário esclarecer que, em primeiro lugar, o momento de turbulência sociopolítica propiciou o aumento da escravidão interna; em segundo lugar, muitos indivíduos não-muçulmanos se diziam convertidos ao islã para tentar fugir da captura e submissão à escravidão nas Américas; em último lugar, até mesmo alguns opositores ao regime islâmico efetivamente se converteram ao Islã quando em Salvador enquanto estratégia de articulação, sobrevivência e autonomia. A jihad no Sudão Central (e, até certa medida, para os povos 
iorubás também), portanto, teve papel fundamental para o deslocamento do ímpeto político militante e revolucionário dos hauçás para as Américas.

Já na África Central, os grupos mais afetados pelo tráfico de africanos tinham raízes culturais muito similares, principalmente no quesito linguístico: os kongo, nos dois lados do baixo do Rio Zaire, e os mbundu e ovimbundu, nas hinterlândias de Luanda e Benguela, respectivamente, todos falando línguas de origem banto (Slenes, 2018). Poucos anos após a chegada da Corte portuguesa ao Rio de Janeiro, o Sudeste-Sul brasileiro viu um fluxo atípico de africanos chegar em seus portos: cerca de $93 \%$ dos traficados eram da África Central, sendo 75\% deles provenientes do lado ocidental. Tal como na África Ocidental, as bacias hidrográficas da África Central muito contribuíram para a interiorização da captura de africanos ao longo do período de escravidão. As bacias dos rios Congo e Kwanza permitiram a interiorização da captura de negros. Por mais que a maior parte dos africanos que embarcaram nos navios negreiros fosse de origem mais próxima do litoral, muitos deles eram filhos de mulheres traficadas no comércio mais interiorano, "tornando-se, com isso, possíveis intermediários culturais entre centroafricanos de origens diferentes" (Slenes, 2018; p. 66).

Os fluxos se tornavam mais ou menos intensos de acordo com a força dos ciclos econômicos do Brasil e de outros eventos de ordem política e social. Por exemplo: a baixa do ciclo do açúcar representa a diminuição dos fluxos para o Nordeste, da mesma forma que a chegada da Corte no Rio de Janeiro em 1808 fez com que aumentasse o número de desembarque de negros vindos da África Central. 
Figura 1: Rotas do tráfico negreiro.

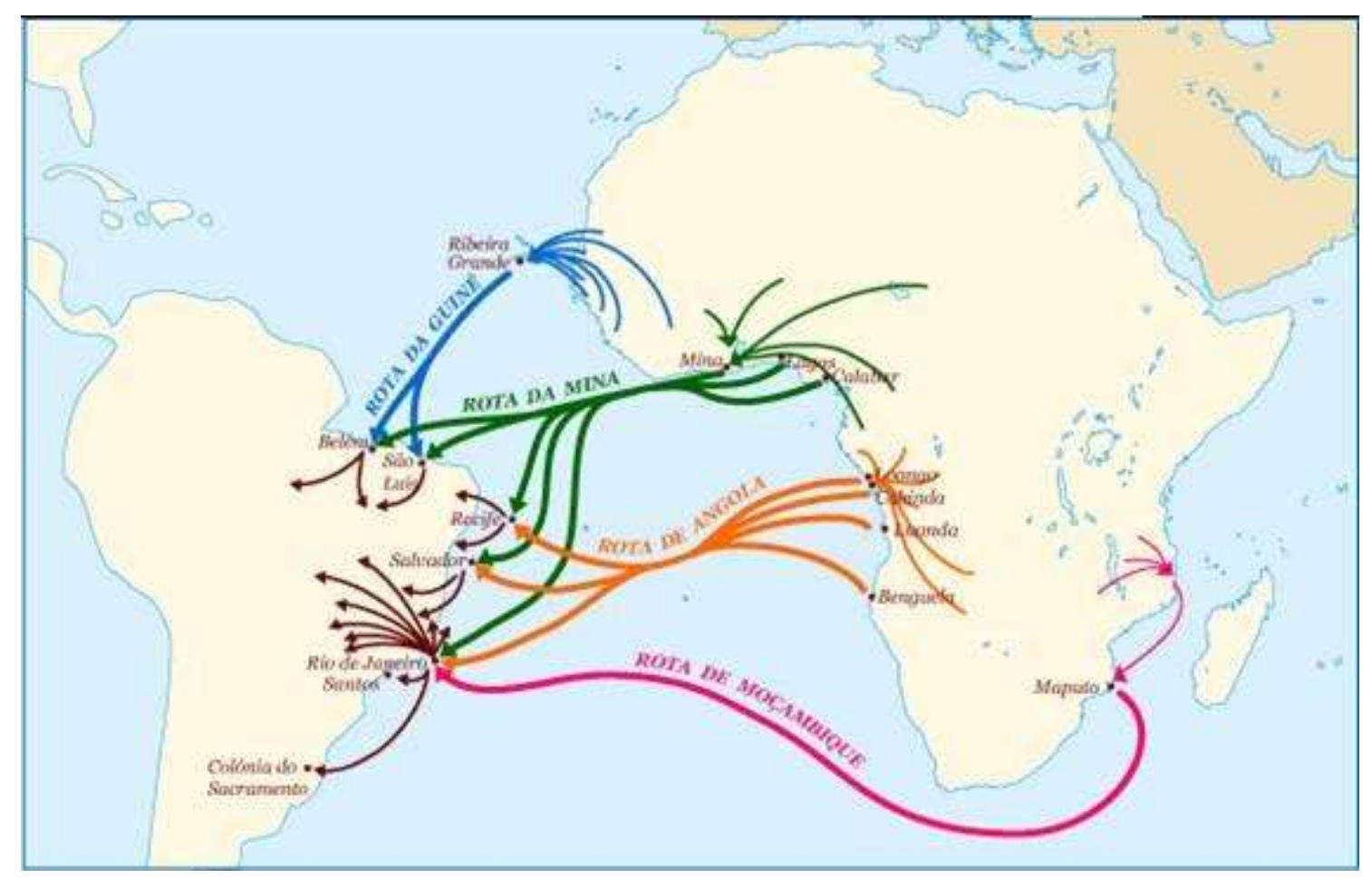

Fonte: https://www.sohistoria.com.br/ef2/culturaafro/p5.php

Torna-se evidente, portanto, que foram vários os povos de origem africana postos em contato direto, e de maneiras muito diversas (nas regiões onde eles eram capturados, nos navios negreiros ou até mesmo nas cidades brasileiras - e em possíveis deslocamentos posteriores entre elas). Não é de surpreender que diante da opressão exercida pelos portugueses em todos esses ambientes eles procurassem estabelecer relações sociais, mesmo que estas fossem breves. São as trocas de recursos culturais realizadas nessas relações que geram o que Gomes (2013) chama de reconfiguração cultural; são essas trocas que deixam as fronteiras das cosmovisões dos escravizados ainda menos definidas, gerando possíveis hibridizações culturais. Para associar essa ideia às trocas comerciais e ao mercado, efetivamente, farei a seguir uma breve explanação sobre as práticas comerciais nas sociedades da África Ocidental e nas da África Central.

\section{KITANDAS E KITANDEIRAS ANGOLANAS}

Segundo Freitas (2015), que fez um belo trabalho de investigação sobre a tradicionalidade das práticas comerciais em Luanda (antiga capital da colônia portuguesa 
na África e atual capital angolana), as kitandas já estavam presentes na paisagem luandense desde o século XVII. O termo de origem quimbundo definia os mercados dominados pelas mulheres - as kitandeiras, que eram de origem banto do grupo mbundu. Elas se dividiam em dois grupos: as mubadi, que eram as funcionárias, e as mukwa, que eram as donas do negócio, e eram responsáveis pela circulação de produtos de diversas categorias pela cidade, principalmente de alimentos.

Quanto à sua presença nos mercados, há dois aspectos que devem ser destacados. O primeiro diz respeito à mobilidade espacial das kitandeiras nos mercados: enquanto algumas negociavam de forma estacionária, havia também aquelas que vendiam seus produtos com cestas se deslocando pelos mercados ou pelas cidades. O segundo aspecto é de cunho mais político: Freitas faz a leitura de que as kitandas eram uma expressão política exercida pelas kitandeiras de se apropriarem do espaço público.

As vendedoras se dividiam nos mercados de acordo com suas etnias, parentescos e com os tipos de produtos que vendiam - artigos alimentícios. comida pronta, amuletos, peças de indumentária etc.

O autor dá destaque ao papel das vendedoras de peixe, uma das mais antigas e organizadas classes de kitandeiras de Luanda. Seu grau de associativismo chegava ao ponto de criação de laços de solidariedade que auxiliavam colegas grávidas durante o período mais delicado da gravidez, dando até auxílio financeiro para as mulheres que haviam se tornado mães recentemente.

Quanto ao papel social fora do ambiente dos mercados, Freitas (2015) diz que as normas sociais baseadas no patriarcalismo reduziam a importância da mulher aos afazeres domésticos. Muitas vezes a participação financeira doméstica de uma mukwa era maior que a do homem (pois sua renda era maior), mas mesmo com a superioridade econômica, seu papel social era hierarquicamente inferior.

\section{MULHERES, COMÉRCIO E ESPIRITUALIDADE NAS SOCIEDADES IORUBAS AFRICANAS}

Segundo Apter (2013), as mulheres das sociedades iorubas no período précolonial africano tinham domínio sobre os mercados das cidades, o que lhes conferia importância simbólica e lugar de prestígio (e de liderança) social. Em termos

Revista da ABPN • v. 12, n. Ed. Especial - Caderno Temático: “Geografias Negras” • abril de 2020, p. 175-199 
institucionais, as mulheres mercadoras eram representadas pelas Iyalodés (título de pessoa mais importante entre as mulheres locais). A manifestação visual deste poder era na indumentária: contas de chefiamento e chapéus que, por vezes, eram usados por líderes de alguns reinos - algo próximo ao que conhecemos como "baiana" no Brasil nos dias de hoje.

Nas crenças iorubas, todas as mulheres carregavam em si o chamado "sangue das mães", uma substância potente que lhes daria a habilidade biológica (aqui lida num sentido mais místico / espiritual do que científico) de dar a luz a bebês. Havia um duplo significado cultura do "sangue das mães" que surtia forte impacto na vida social das mulheres: ele era, por um lado, positivo pelo seu potencial procriador (quando se unisse ao sêmem masculino); por outro, era negativo pela negação da criação da vida - um "sangue ruim" temido pelos homens que acreditavam que ele poderia neutralizar seus remédios pelo simples contato físico. Além disso, enquanto menstruavam as mulheres simbolizavam fertilidade, energia procriativa e reprodutiva, pois deixavam fluir o asé para fora; após a menopausa, o sangue "aprisionado" no corpo aumentaria o seu asé e, portanto, o poder de seus feitiços.

A ocorrência ou não da menstruação de uma mulher afetava seu privilégio social enquanto comerciante: quanto mais velha ela fosse, mais respeito ela inspirava e mais próspera ela era considerada. Uma mulher mais velha teria mais habilidade para o comércio pois dedicaria mais tempo às trocas comerciais do que com seus afazeres domésticos ou cuidando de seus filhos. Ao mesmo tempo ela era vista como uma ameaça ao patriarcado.

As mercadoras se organizavam em pequenas associações egbé, que ajudavam a consolidar sua influência e seu poder frente às autoridades masculinas e quanto mais velha fosse a mulher, mais prestígio entre as próprias mercadoras ela tinha, se tornando uma possível liderança social; dentro de casa, o acúmulo econômico interferia na sua participação nas economias domésticas e, portanto, nas decisões financeiras, o que reduzia o poder masculino no ambiente doméstico (APTER, 2013).

O que talvez possa diferenciar as mulheres vendedoras iorubás das quitandeiras bantos é justamente esse elemento cultural do "sangue das mães". Seu significado místico gerava tensão nas relações de gênero dentro e fora dos mercados e dava relavância à figura da mulher na sociedade ioruba - por exemplo: o festival de carrying water era um evento

Revista da ABPN • v. 12, n. Ed. Especial - Caderno Temático: "Geografias Negras”• abril de 2020, p. 175-199 
regular onde mulheres mercadoras realizavam rituais para trazer o poder dos orixás para as cidades e revitalizar a comunidade.

Importante apontar que as mulheres tinham múltiplas funções no comércio ioruba (RAJI, OLUMOH, ABEJIDE; 2013) já desde muito antes do jihad muçulmano, do surgimento do Califado de Sokoto e das reformas políticas islâmicas na estrutura social ioruba. Muitas dessas funções inclusive se mantêm até os dias de hoje. Enquanto os homens estavam envolvidos com expedições militares, elas se tornaram fundamentais para a estabilidade econômica não só doméstica, mas das cidades. Elas estavam envolvidas em atividades de comércio, funilaria, agricultura, indústria de vestimentas etc. Segundo os autores, dentro do comércio, elas eram responsáveis pelo comércio a curta e a longa distância, pelo comércio doméstico, vendas a atacado e a varejo e pela venda ambulante nas ruas. Seus produtos envolviam bens domésticos, produtos importados, joias, óleo, peixes, vegetais e outros (p. 46). Além disso, elas eram encarregadas também da operacionalização dos mercados de diversas regularidades (periódicos, os de 5 dias, os de 9 dias e os mercados noturnos). Aquelas que não tinham recursos financeiros o suficiente para terem seus próprios negócios atuavam como atendentes, carregadoras, artesãs aprendizes e ambulantes vendedoras de produtos que vinham das fazendas (p. 48). Haviam também que, também por não terem recursos o suficiente para investir em negócios próprios ou por saberem falar mais de um idioma, atuavam como intermediadoras entre vendedores e compradores, recebendo uma comissão por cada transação realizada (p. 49). As comerciantes especializadas na venda de alimentos costumavam vender um tipo específico de comida e começaram, historicamente, com a venda ambulante, mas começaram a estabelecerem pontos permanentes (chamados de "centros de comida") conforme a população aumentava.

Tudo isso reforça a tradição e a autoridade que as mulheres iorubas tinham no comércio e no mercado de suas sociedades. É curioso notar, como faremos adiante neste trabalho, como muitas dessas práticas foram observadas nas cidades de Salvador e do Rio de Janeiro durante o período imperial.

\section{A HERANÇA EM PRÁTICA: O COMÉRCIO DAS GANHADEIRAS EM SALVADOR}

\footnotetext{
Revista da ABPN • v. 12, n. Ed. Especial - Caderno Temático: "Geografias Negras”. abril de 2020, p. 175-199
} 
No século XIX, as relações escravistas no Rio de Janeiro e em Salvador se davam majoritariamente através do sistema de ganho, caracterizado pela venda de produtos (dos próprios comerciantes, dos senhores ou de pequenos produtores) por parte dos escravizados, que pagavam semanalmente uma cota pré-estabelecida ao senhor - o jornal (SOARES, 2013) - podendo guardar para si o restante; ao fim de determinado período, essa sobra possibilitava o escravizado de comprar sua alforria. Por outro lado, essa mesma transação permitia que o senhor comprasse outros negros para que estes entrassem em regime de ganho.

No Rio de Janeiro, esses comerciantes negros eram conhecidos como negros de ganho; em Salvador, o nome comum atribuído a eles era ganhadores.

O sistema de ganho era, de fato, o caminho "mais fácil” para se comprar a alforria, principalmente após a assinatura da Lei do Ventre Livre (1871), e também o que dava ao negro maior autonomia - pelo menos no que tange o deslocamento espacial e controle de suas finanças. Segundo Soares (1996), o retorno financeiro variava de acordo com o gênero, ocupação, idade, habilidades pessoais, condições de saúde etc.

Uma ruptura cultural em relação ao que se tinha entre a colônia portuguesa e as iorubás é que na primeira o trabalho masculino era muito mais valorizado economicamente do que o das mulheres, até mesmo no comércio - ainda que elas representassem a maioria quantitativa nessa atividade. O retorno financeiro aos homens chegava a ser o dobro. Sempre que possível, as ganhadeiras preferiam viver fora das casas dos senhores, pois assim teriam maior controle da própria vida, da própria mobilidade e de suas economias.

Mulheres libertas também participavam do comércio de rua. Estima-se que 79\% das mulheres africanas libertas de Salvador se dedicavam a essa atividade. Não havia senhores para interferir na vida pessoal ou nos negócios e seus produtos lhes pertenciam; apenas as dinâmicas espaciais eram as mesmas que as das mulheres escravizadas.

Era justamente a tradição comercial das mulheres africanas (ainda em África) que as colocava nessa função social comercial em Salvador. Sabendo das tradicionais habilidades comerciais que as mulheres tinham na África pré-colonial, os próprios senhores escravagistas esperavam, antes mesmos da contratação, que elas atuassem no comércio em terras brasileiras, como apontado por Soares (1996) e Apter (2013). 
Durante o século XIX a cidade de Salvador passou pelo aceleramento de seu processo de urbanização. Ao mesmo tempo, a economia baiana passou a girar em torno do açúcar - o que deixou o cenário da economia de subsistência e de consumo interno muito fragilizado. E foi nessa brecha que se observou a ascensão social das ganhadeiras, visto que elas se aproveitaram dessa fragilidade para se inserirem de vez no pequeno comércio. Tal como observado em África, elas eram organizadas e bem articuladas entre si. Suas redes e distribuição geográfica pela cidade preocupavam as autoridades de Salvador, que faziam o possível para interferir nas suas atividades.

As ganhadeiras tiveram uma ascensão muito bem sucedida, chegando a um lugar de grande relevância social na Bahia, mesmo diante de um cenário onde o trabalho dos homens negros era economicamente mais valorizado, onde fiscalizações eram comumente arbitrárias e posturas de autoridades dificultavam suas atividades. A hostilidade se agravou após a Revolta dos Malês, em 1835, liderada por negros hauçás (povos fortemente influenciados pela cultura islâmica), mas que também teve participação de africanos iorubás.

Esta revolta, inclusive, foi um momento de intensificação das tensões entre colonos, elite baiana e africanos. Criou-se repulsa à "índole rebelde" dos negros minas, uma fama que chegou a outras províncias brasileiras. Há, inclusive, suspeitas de que as ganhadeiras foram responsáveis pela distribuição de alimentos para os manifestantes da Revolta dos Malês.

Após o fracasso da Revolta, controlar os africanos se tornou uma questão urgente. Essa urgência era refletida nas relações sociais e nas políticas públicas. A classe senhorial passou a vender os cativos africanos para senhores de outras províncias; havia a imposição de taxas de matrícula para atuação como ganhadeiros, que eram significativamente mais caras para negros africanos do que para crioulos. Tudo isso contribuiu para movimentos de deslocamento em massa de negros africanos para o Centro-Sul brasileiro ou para a deportação de parte deles de volta para o continente africano.

\section{TODOS OS CAMINHOS LEVAM À CORTE: IORUBAS E BANTOS NO COMÉRCIO DE RUA DO RIO DE JANEIRO}


Como dito anteriormente, dois eventos foram fundamentais para o aumento do fluxo de negros escravizados para o Rio de Janeiro: a chegada da Corte Imperial, em 1808, e o fim da Revolta dos Malês na Bahia, em 1835. Com o tempo, esse fluxo diminuiu, mas seguiu existente mesmo após a proibição do tráfico de escravizados em 1850 - esse tráfico se manteve nos deslocamentos interprovinciais (a perseguição religiosa em Salvador foi um fator agravante para isso) e, em alguns casos excepcionais, pelas navegações (Sampaio, 2009).

À época, haviam poucos setores profissionais urbanos na cidade do Rio de Janeiro. A economia urbana carioca dependia fundamentalmente da população escravizada, que representava mais da metade da população - boa parte nas atividades comerciais do ganho. Em 1810, o Príncipe Regente regularizou essa dependência preocupava a Corte, principalmente sob as notícias de uma revolta de escravizados bem sucedida no Haiti, a primeira da América Latina. Para não correr riscos, o príncipe regente Dom João criou, em 1809, a Divisão Militar da Guarda Real de Polícia, instituição seminal do que hoje conhecemos como Polícia Militar do Estado do Rio de Janeiro.

Em 1810, reconhecendo a necessidade das atividades comerciais para urbanizar e modernizar a cidade, o Príncipe Regente regulamentou oficialmente as atividades comerciais no espaço urbano carioca - mesmo sem prever que essa constante duraria por mais de cem anos adiante. O artista francês Jean Baptiste Debret, um dos maiores retratadores do cotidiano urbano carioca colonial e que ficou na cidade de 1816 a 1831 pela Missão Artística Francesa, chegou a afirmar que no ano de 1816 cerca de três quintos da população carioca é composta por negros de ganho (Martins, 2006).

Nesse momento observa-se um dilema prático por parte das autoridades: a população negra é ao mesmo tempo uma ameaça às ordens política e urbana e também uma necessidade econômica. Teme-se o negro, mas precisa-se desse mesmo negro.

Participavam do ganho negros libertos ou aqueles que ainda estavam (constitucionalmente) sob regime escravocrata. Inicialmente, eles apenas carregavam os produtos para os senhores. Carvalho afirma, inclusive, que "carregar qualquer coisa era atividade escrava; na cultura senhorial urbana, quem era livre só levava nas mãos objetos de estrito uso pessoal, como um lenço ou uma bengala" (2018, p. 158), o que sublinha o ato de "carregar algo publicamente" como um marcador social de condição de escravizado. Foi apenas após 1830 que os negros passaram a realizar as negociações e

Revista da ABPN • v. 12, n. Ed. Especial - Caderno Temático: “Geografias Negras” • abril de 2020, p. 175-199 
trocas comerciais na vendagem ambulante a partir de um tipo de treinamento imposto pelos senhores escravistas (Martins, 2006). Eles andavam pelas ruas de porta em porta fazendo o pregão de seus produtos, ou organizavam-se em pequenos aglomerados pelas ruas.

Após 1835, a chegada de africanos de origem ocidental no Rio de Janeiro foi acompanhada pelos olhos atentos das autoridades. Os negros minas, como passaram a ser chamados todos aqueles de origem dos povos sudaneses (ou seja, os que não eram negros angolas, bantos) representavam ameaça à ordem urbana. Portanto, surgia uma maior necessidade de exercer o controle social sobre eles. A maior parte dos negros vindos da Bahia a partir de 1850 tinha problemas legais com a Corte; entre 1860 e 1888, 386 negros que tiveram passagem pela Bahia chegaram a ser presos na Casa de Detenção da Corte (Sampaio, 2009).

Especula-se que os africanos iorubás vinham para o Centro-Sul brasileiro por diferentes motivações. Dentre algumas que Soares levanta hipótese (2001), estão o grau de urbanização do Rio de Janeiro da década de 1830, que estaria próximo ao observado nas vilas e cidades iorubás no continente africano, a fuga da perseguição pós-Revolta dos Malês (o que é diferente da negociação de escravizados entre os senhores das duas cidades) e a busca por condições urbanas de vida semelhantes para aqueles que já eram bem-sucedidos no ganho. Sampaio (2009) argumenta outros dois motivos que podem ter influenciado nessa migração voluntária para o Rio de Janeiro: a busca por familiares que pudessem ter vindo diretamente da África ou que pudessem ter sido negociados anteriormente com o Rio e a escravidão como negócio, visto que muitos baianos vinham para o Sudeste na intenção de investir nesse mercado para sobreviver da cobrança de aluguel de negros escravizados.

O ganho de rua era a principal ocupação profissional para os negros em solo carioca. A atividade, que já era realizada desde antes mesmo do decreto de 1810 do Príncipe Regente, tornou-se uma ferramenta de grande relevância para a população negra. Essa relevância se dava de três maneiras, algumas delas já apresentadas anteriormente neste trabalho: i) o ganho como fonte de renda, que, tal como em Salvador, era o melhor caminho para ii) conquistar a alforria e alcançar certo prestígio social e iii) era um dos melhores ambientes para participar de redes de articulação entre negros em solo carioca. 
No Rio, os homens tinham maior presença nas atividades de ganho do que em Salvador. Ainda assim, as representações do cotidiano urbano carioca costumam dar destaque à presença feminina na ambulantagem, como nas pinturas de Debret. Elas percorriam as ruas e becos da área central da cidade, ocupavam praças com seus produtos e caldeirões e os mercados com suas barracas, como podemos ver na pintura "Negras cozinheiras, vendedoras de angu", de Debret, apresentada na Figura 2 a seguir.

Figura 2 - Negras cozinheiras, vendedoras de Angu

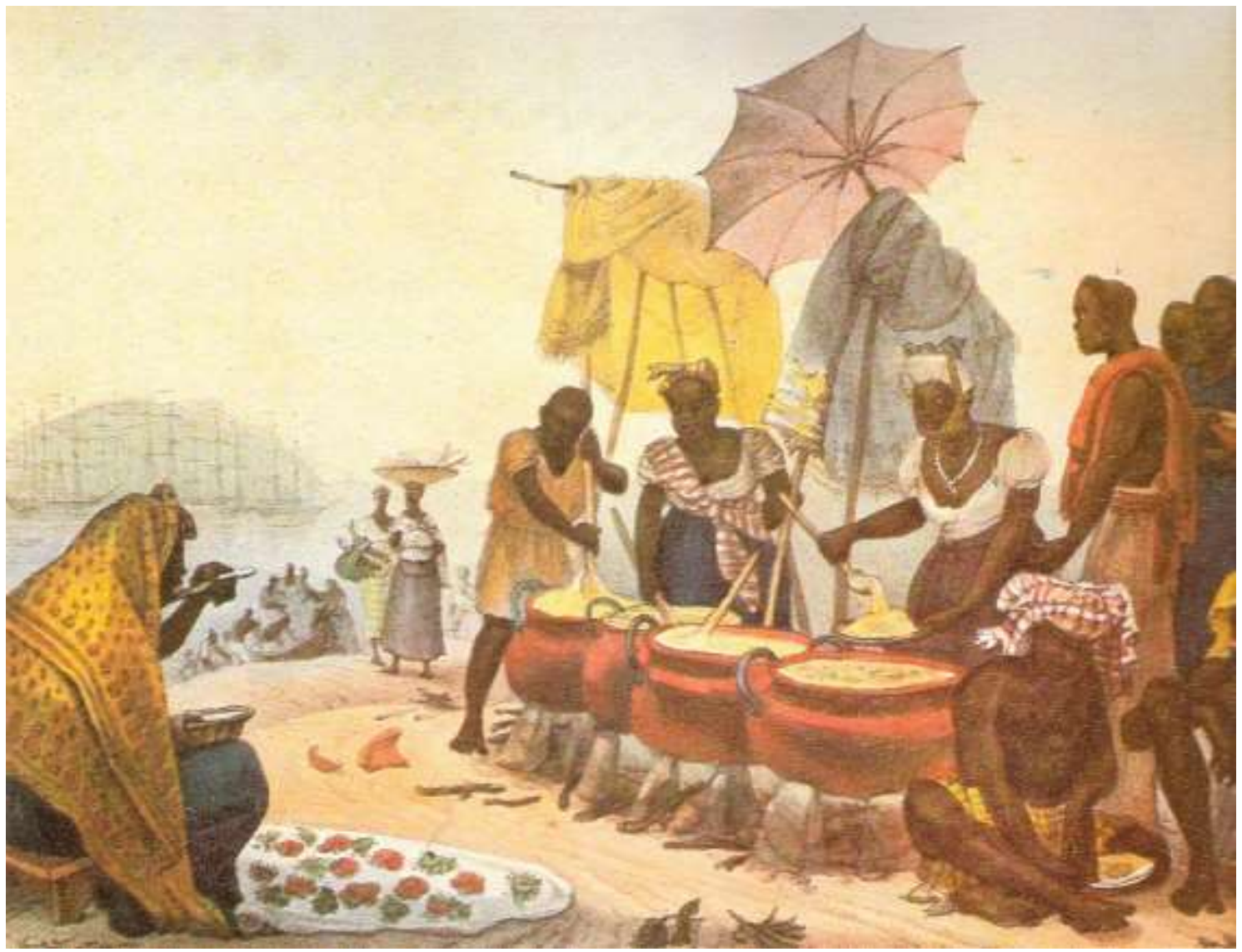

Fonte: http://gangamacota.blogspot.com/2012/09/negras-cozinheiras-vendedoras-de-angu.html (Jean-Baptiste Debret, c. 1815-1831)

A chegada dos minas no Rio misturou as "nacionalidades" que atuavam no ganho de rua. Na verdade, as mulheres minas tiveram relevância muito grande nessa ocupação. Primeiro porque, segundo Soares (2001), quase 100\% delas atuaram como quitandeiras na cidade, o que refletia no número absoluto dos praticantes dessa ocupação. Segundo porque, ainda pelo mesmo autor, elas se deslocavam mais pelas ruas da cidade por serem mais embativas e resistentes nos momentos de disputa de ponto e de confronto com 
autoridades e com ladrões, e esse deslocamento contribuiu para a interiorização do comércio.

Em terceiro lugar, elas tinham uma capacidade de articulação muito bem desenvolvida, o que contribuiu para a formação de redes de escravizados (livres, libertos ou ainda escravizados, urbanos e do campo) que eram muito úteis para a população negra - e isso pode ter sido impulsionado pela interiorização do comércio. Havia um tipo de estabelecimento chamado casa de angu (ou zungús), que poderiam ser ou uma ocupação temporária do espaço público, ou um imóvel. Nessas casas de angu se davam encontros onde negros de todas as "nacionalidades" e condições sociais sociabilizavam, trocavam informações e produtos e praticavam rituais de religiões de matriz africana. A maioria desses zungús eram administradas por negros mina. Quando em imóveis, essas casas serviam também de abrigo, dormitório ou refúgio para escravizados fugidos tanto do espaço urbano quanto das fazendas.

Essa rede era interessante até mesmo para a troca de informações para aqueles que buscam encontrar familiares conterrâneos na nova cidade, como aponta Sampaio (2009). Há casos, inclusive, em que as redes de quitandeiras eram eficientes a ponto de facilitar a fuga de negros para fora do país. Soares (2001) dá o exemplo de Paula, negra mina de 35 anos, que na década de 1860 chefiava um esquema de fuga de negros por navios para os Estados Unidos após sua abolição da escravidão em 1863.

Principalmente na segunda metade do século XIX, a apropriação do termo "mina" por parte das mulheres iorubás foi parcialmente consciente, como alega Soares (2001). Havia a intenção de se criar uma rede articulada de negras baianas. Esta é, possivelmente, uma estratégia de sobrevivência forjada em momentos de deslocamento - no caso, um deslocamento interprovincial.

Um quarto aspecto de grande influência no prestígio social dos minas em solo carioca foi de ordem espiritual. A maneira como eles eram vistos por outros negros, principalmente por mulheres africanas e crioulas, gerava impacto social. Principalmente as mulheres eram vistas como "depositárias de uma já longínqua tradição religiosa" que reconectava os negros africanos às práticas sociais de sua terra natal, principalmente através das crenças, da fé - reforça-se aqui o poder dos zungús (Soares, 2001; p.68). As religiões dos povos sudaneses reverberavam nas articulações de relações sociais de maneira muito mais efetiva do que as de dos povos banto. Isso garantiu às negras minas

Revista da ABPN • v. 12, n. Ed. Especial - Caderno Temático: “Geografias Negras” • abril de 2020, p. 175-199 
prestígio social. Mas era esse mesmo caráter religioso que fazia com que negros minas (mulheres e homens) fossem perseguidos, mesmo que em alguns casos os seus senhores os protegessem (Sampaio, 2009).

\section{CONCLUSÃO: CONTINUIDADES E RUPTURAS DE UMA DIÁSPORA COMERCIAL}

Portanto, tínhamos em solo carioca as quitandas e zungús, terminologias de origem banto, lugares e práticas inicialmente relacionados a uma presença majoritariamente banto, mas que com o tempo se viu misturada com um grande contingente de negros sudaneses (minas, iorubas, hauçás etc.) que contribuíram para a articulação da comunidade negra no Rio de Janeiro - muitos atribuem o surgimento da Pequena África Carioca a essa articulação, recaindo ainda às baianas papéis de centralidade ([algo questionado por alguns estudiosos, como Clementina Cunha (2001) e Gabriela Sampaio (2009))]. Numa noção de Andrelino Campos (2014) a partir de Santos (2007), pode-se dizer que as relações entre os negros tanto em solo baiano quanto em solo carioca se dão predominantemente por horizontalidades, ou seja, numa circulação de informações e valores geralmente estabelecidas territorialmente e por grupos sociais muito semelhantes.

As relações de horizontalidade contribuíram para que alguns traços do significado cultural dos mercados se mantivessem. Waldman (2016) lembra que, diferentemente do que para os europeus, para os africanos os mercados significavam mais do que um lugar de relações econômicas: "funcionalmente, o mercado africano foi uma contrapartida à autarquia da sociedade tradicional, fortalecendo laços e o sentimento de solidariedade e da consciência do coletivo numa periferia geográfica mais dilatada" (p. 10). Os zungús nas praças e nos imóveis representam o caráter de socialização entre africanos - a ponto de, em 1820, o viajante inglês Chamberlain observar um certo número de negros numa praça carioca onde haviam negros de ganho reunidos e registrar que via "negros indolentes e tagarelas" entregues ali à "inclinação natural de escutar a conversa dos outros" (In: Martins, 2006; p. 83).

O associativismo e a solidariedade não só se mantiveram como se ampliaram: se antes as mulheres se organizavam para ajudarem umas às outras, no Brasil o auxílio

Revista da ABPN • v. 12, n. Ed. Especial - Caderno Temático: "Geografias Negras”• abril de 2020, p. 175-199 
passou a não ser apenas entre elas e ia também para o campo da compra de alforrias, formação de redes de informações e de redes auxílio àqueles que quisessem fugir, participação em levantes de escravizados, refúgio a negros fugidos etc.

Esse mesmo associativismo e o ímpeto político de negros (principalmente dos hauçás e iorubas), somado à sua proficiência comercial, podem ser entendidos como heranças dos contatos desses povos com os muçulmanos. Apter (2013, p. 91) cita a historiadora Hilary Beckles para demonstrar as práticas do comércio por mulheres iorubás no Caribe não apenas como uma ocupação social, mas também como uma forma de resistência e de reprodução da cultura iorubá: “os escravizados lutaram pelos direitos de serem legítimos, agentes econômicos autônomos, como se essa fosse a única maneira de preservar aspectos da herança comercial que eles trouxeram para o Novo Mundo" (tradução livre). Considerando que a maior parte dos escravizados levados para a América Central também são originários dos reinos do Golfo da Guiné, é possível ao menos supor que o sentimento de "herança" em relação à prática do comércio é semelhante.

Por outro lado, todas as relações entre negros africanos e crioulos se davam num ambiente colonial/imperial onde as autoridades, para dizer o mínimo, reduzem os africanos a meros corpos biológicos, esvaziando-os de boa parte das suas experiências e/ou trajetórias de vida, se apropriando dos traços culturais que lhes fossem convenientes, deixando apenas o que lhes alertasse como ameaça, como o medo de suas crenças religiosas e o temor por revoltas - retomando ao início do texto, negando aos negros o exercício e validade social e política de suas cosmovisões. Nesse sentido, e evocando novamente Campos, essas relações tendem mais a relações de verticalidade, onde as diferenças entre indivíduos e grupos sociais surgem no encontro e se manifestam na predominância daqueles que são socialmente hegemônicos.

Mbembe diz que a condição escrava resulta numa tripla perda: "perda de um 'lar', perda de direitos sobre seu corpo e perda de estatuto político" (2018, p. 27). E quando Hall (2016; p. 48) fala de "sociedades diaspóricas", "sociedades de deslocamento e disjunção, separadas temporal e espacialmente de qualquer coisa que pudesse ser colocada ou ser construída, de forma decisiva, como seus locais de origem”, ele se refere a essa dificuldade por parte dos grupos esvaziados de seu estatuto político não só de terem êxito na insurgência, visto que algumas revoltas de escravizados foram controladas antes mesmo de começarem (perda do estatuto político), mas também, e antes mesmo, de

Revista da ABPN • v. 12, n. Ed. Especial - Caderno Temático: “Geografias Negras”• abril de 2020, p. 175-199 
estabelecerem um sentimento de pertencimento à terra (perda do lar), de se organizarem social e territorialmente devido ao excessivo exercício do controle social dos grupos sociais que pretendem manter e reproduzir socialmente seus privilégios (perda do controle sobre o corpo) - grupos esses que vivem no dilema prático, pois ao passo que querem isso, também dependem economicamente dos grupos oprimidos.

Nas palavras do próprio Hall,

em nossa parte do Atlântico Negro, os nativos foram dizimados pelo trabalho pesado e pela doença nos primeiros cem anos de colonização. A terra não pode ser "sagrada", pois foi violentada: não ficou vazia, foi esvaziada. Todos ali pertenciam a outro lugar em determinado momento. Longe de ser a continuidade de nossos passados, nossas histórias são marcadas por rupturas violentas e abruptas. Em vez de evolução gradativa da associação civil, tão central ao discurso liberal da modernidade ocidental e da nação, nossa "associação civil" foi inaugurada por um ato brutal de vontade imperial (Hall, 2016, p. 49-50).

Quanto à importância do mercado nas culturas iorubá e banto, podemos observar como uma importante ruptura causada pelas verticalidades a participação dos homens no âmbito comercial e na vida espiritual / religiosa da comunidade negra, o que fez com que se reduzisse a importância da mulher do comércio nessa esfera, ao menos pelo aspecto financeiro. Enquanto no continente africano a presença da mulher tinha um forte significado social (e espiritual, como no caso das mulheres iorubás e o "sangue das mães"), onde a prática do comércio era feita quase que exclusivamente pelas mulheres, no Brasil os homens passaram a ter mais relevância na prática do ganho de rua. Em Salvador, eles chegavam a ter um retorno financeiro muito maior do que as mulheres; no Rio de Janeiro, até mesmo na esfera religiosa-espiritual eles passaram a atuar - Sampaio (2009) cita os casos do pai de santo Pereira Sodré em Salvador, preso em 1862, e de Juca Rosa, o Pai Quilombo, e Antão Teixeira, importantes líderes religiosos para os negros na cidade do Rio de Janeiro. O primeiro foi preso em 1875 e logo depois o segundo foi deportado para o continente africano. Não se sabe, entretanto, e é questionável, se a entrada dos homens na vida espiritual da população negra se deu, a priori, pela perda imposta da importância social da figura da mulher negra, ou se isso também foi uma estratégia de articulação das redes de africanos e crioulos; apreende-se apenas essa mudança nas relações sociais de gênero. 
É perfeitamente possível que a importância das mulheres negras para o comércio tenha sido reduzida devido à caricaturação de suas imagens. Se no Caribe, como Apter (2013) aborda, surgiram as imagens da dócil e servil Mammy e da hiperssexualizada Jezebel, no Brasil tivemos as amas de leite e a figura da mulata, respectivamente. Ou seja, além de esvaziar as mulheres negras de humanidade e dignidade, a elas foram atribuídos estigmas que as submetiam ao controle de seus corpos e de sua força de trabalho. Por mais que esses estigmas estivessem mais relacionados às escravizadas em ambiente doméstico, alguns deles também recaíam sobre as quitandeiras.

Outro fenômeno que demonstra a ruptura religiosa está no sincretismo religioso observado durante o século XIX e isso também está relacionado aos mercados. Tomemos como exemplo a Rua Uruguaiana, que desde o século XIX já era preenchida por vendedores por toda a parte, como Brasil destaca nesse relato:

os vendedores de hortaliças e legumes, tudo num alvoroço constante, numa mistura de brancos e pretos de todos os feitios, num apregoar sem fim das boas condições de seus produtos das hortas ou das 'babas de moça' que as 'sinhás' andavam vender pelas suas 'negras de ganho' para o melhoramento das finanças caseiras ou dos negros barbeiros e aplicadores de chifres, a chamar clientes para as suas habilidades de artistas e curadores de volantes..." (Gerson, 2015, p. 107).

A Igreja Nossa Senhora do Rosário, que se encontra até hoje nessa mesma rua, tinha uma grande importância para a população negra do Rio de Janeiro, visto que ali eram realizadas muitas reuniões e festejos desse estrato da sociedade. As festas tinham elementos de religiões de matriz africana, mas eram essencialmente católicas. Ceder à religião católica, no caso, não era apenas uma submissão à normativa social colonial/imperial, mas também uma forma de negociação entre negros e autoridades brancas: Carvalho (2018) identifica esses eventos religiosos, muitas vezes organizados por irmandades negras, como estratégias de resistência negra, pois "essas irmandades procuravam proteger seus irmãos e intermedia as relações com as autoridades".

Desses exemplos, podemos pensar o termo etnocídio discutido por Correia (2011). A partir da ideia de domínio como o estabelecimento de uma relação de poder "através do controle e da destruição do corpo, visando o extermínio de traços culturais responsáveis pela perpetuação de um grupo humano" (p. 39), ele narra brevemente a

Revista da ABPN • v. 12, n. Ed. Especial - Caderno Temático: “Geografias Negras”• abril de 2020, p. 175-199 
história desse conceito em contextos de debates políticos ao redor do mundo. Desse debate, podemos destacar: a ideia de genocídio cultural como um conjunto de atos que contribuem para a censura e destruição de língua, religião e outros traços característicos de uma dada cultura; o termo etnocídio como um processo de "des-civilização"; e, por fim, a ideia de etnocídio como a negação a um grupo social de "desfrutar, desenvolver e transmitir sua própria cultura e sua língua", como consta na Declaração de San José de Etnodesenvolvimento e Etnocídio na América Latina (In: VIEIRA, 2011).

E é nesse sentido de tentativas de domínio, silenciamento e negação que se deram essas rupturas do significado simbólico e cultural para os africanos tanto do ambiente do mercado, quanto daqueles (ou daquelas) que protagonizavam as atividades comerciais. No constante sufocamento da liberdade da população negra não apenas constitucional, mas também de circulação, do ir e vir, de estar e de ser; era-lhes permitido apenas o que fosse conveniente às elites sociais. Era a dependência econômica que a elite colonial tinha das atividades dos escravizados que conferia à população oprimida uma paradoxa "liberdade limitada" - que perdura até os dias de hoje.

Por outro lado, foi exatamente nas brechas dessa "liberdade limitada" que a população negra encontrou meios de fazer não só com que ela, em seus corpos, resistisse, mas também com que as próprias culturas também se mantivessem vivas. As quitandeiras, carregando todas as suas tradições sociais e espirituais desde África (inclusive na indumentária, que se transformou em importante marcador social e religioso na paisagem urbana), tiveram papel fundamental nessa resistência, para que não apenas rupturas pudessem ser citadas neste trabalho.

A exemplo disso, podemos citar a proeminência de figuras como Sabina das Laranjas, baiana que vendia frutas próximo à Faculdade de Medicina, e que após ser proibida de ocupar seu ponto recebeu uma mobilização dos próprios estudantes de medicina para que ela pudesse voltar ao exercício de profissão; e Tia Ciata, a matriarca do samba, que após curar um machucado na perna do então presidente da república Wenceslau Braz deixou de ser perseguida pelas autoridades repressivas da época - fato que marcou o início do deslocamento da herança africana do comércio das ruas para o ambiente doméstico, visto que ela e outras tias baianas (Calu Boneca, Maria Amélia, Pepétua e tantas outras) levaram para dentro de suas casas a sociabilidade negra em torno da comida (quitutes e angu), o que está diretamente associado à formação da Pequena

Revista da ABPN • v. 12, n. Ed. Especial - Caderno Temático: “Geografias Negras”• abril de 2020, p. 175-199 
África e pro surgimento das rodas de samba no Rio de Janeiro. Mulheres negras que invariavelmente se foram confundidas em seus próprios problemas, mas que ainda assim deixaram sua marca e seu legado para a população e para a cultura negra brasileira.

\section{REFERÊNCIAS BIBLIOGRÁFICAS}

"NEGRAS cozinheiras, vendedoras de angu - Jean Baptiste Debret". 2012. Disponível em: http://gangamacota.blogspot.com/2012/09/negras-cozinheiras-vendedoras-de-angu.html. Acesso em: 02 jan. 2019.

"Rotas da escravidão" em Só História. Virtuous Tecnologia da Informação, 2009-2020. Consultado em 07/03/2020 às 19:48. Disponível na Internet em http://www.sohistoria.com.br/ef2/culturaafro/p5.php

ALENCASTRO, Luiz Felipe de. África, Números do Tráfico Atlântico. In: SCHWARCZ, Lilia M.; GOMES, Flávio. Dicionário da Escravidão e Liberdade. São Paulo: Companhia das Letras, 2018. p. 57-63.

APTER, Andrew. The blood of mothers: women, money, and markets in yoruba-atlantic perspective. The Journal Of African American History, [s.1.], v. 98, n. 1, p.72-98, jan. 2013. University of Chicago Press. http://dx.doi.org/10.5323/jafriamerhist.98.1.0072. Disponível em: $<$ https://www.jstor.org/stable/10.5323/jafriamerhist.98.1.0072>. Acesso em: 18 ago. 2019.

CAMPOS, Andrelino. Movimento em estruturas "sócio-espaciais": em busca dos sujeitos subalternos. In: SILVA, Catia Antonia da; CAMPOS, Andrelino; MODESTO, Nilo Sergio D'avila. Por uma geografia das existência: movimentos, ação social e produção do espaço. Rio de Janeiro: Consequência, 2014. Cap. 2. p. 47-66.

CARVALHO, Marcus J. M. de. Cidades Escravistas. In: SCHWARCZ, Lilia M.; GOMES, Flávio. Dicionário da Escravidão e Liberdade. São Paulo: Companhia das Letras, 2018. p. 156162.

CORREIA, Gustavo José. Breves notas sobre a concepção de etnocídio e seu contexto como violação de direitos humanos. Lex Humana, Petrópolis, v. 3, n. 1, p.36-49, jun. 2011. Disponível em: <http://seer.ucp.br/seer/index.php/LexHumana/article/view/106>. Acesso em: 22 ago. 2019.

FRANÇA, Carolina Rebouças; REZENDE, Vera. A permanência e o desaparecimento dos mercados municipais e feiras livres nos espaços urbanos cen-trais das cidades do Rio de Janeiro e de Salvador, Brasil. Seminário Internacional Urbicentros, Salvador, 2012. Disponível em: $<$ http://www.ppgau.ufba.br/urbicentros/2012/ST225.pdf $>$. Acesso em: 09 mar 2016

FREITAS, Fernando Vieira de. Das kitandas de Luanda aos tabuleiros das Terras de São Sebastião: conflito em torno do comércio das quitandeiras negras no Rio de Janeiro do século XIX. 2015. 122 f. Dissertação (Mestrado) - Curso de Planejamento Urbano e Regional, Instituo de Pesquisa de Planejamento Urbano e Regional, Universidade Federal do Rio de Janeiro, Rio de Janeiro, 2015. Disponível em: <http://objdig.ufrj.br/42/teses/858668.pdf>. Acesso em: 29 ago. 2019. 
HALL, Stuart. Diásporas, ou a lógica da tradução cultural. Matrizes, São Paulo, v. 10, n. 3, p.47-58, dez. $2016 . \quad$ Disponível em: $<$ https://www.google.com/url?sa=t\&rct=j\&q=\&esrc=s\&source=web\&cd=5\&ved=2ahUKEwj81 u7ZgcfkAhW2HbkGHf3NCU0QFjAEegQIAxAB\&url=https\%3A\%2F\%2Fwww.revistas.usp.br \%2Fmatrizes\%2Farticle\%2Fdownload\%2F124647\%2F121877\%2F\&usg=AOvVaw2z18A4q1X 2BtsQbNThi-JS>. Acesso em: 15 out. 2018.

LOVEJOY, Paul E.. Jihad e escravidão: as origens dos escravos muçulmanos da Bahia. Topoi, Rio de Janeiro, v. 1, n. 1, p.11-44, dez. 2000. Disponível em: $<$ http://www.scielo.br/pdf/topoi/v1n1/2237-101X-topoi-1-01-00011.pdf $>$. Acesso em: 04 jan. 2020 .

MARTINS, Angela Maria Moreira. 2006. Ambiências que abrigam o comércio informal no Rio de Janeiro: O estudo de caso do Mercado Popular da Uruguaiana. In: GOMES, Maria de Fatima Cabral Marques (Org.). Cidade, -transformações no mundo do trabalho e políticas públicas: A questão do comércio ambulante em tempos de globalização. Rio de Janeiro: DP\&A Editora

MBEMBE, Achille. Necropolítica: Biopoder, Soberania, Estado de Exceção e Política de Morte. São Paulo: N-1 Edições, 2018.

RAJI, A. O. Y.; OLUMOH, A. O.; ABEJIDE, S. T.. Women and Their Role in the Economy of Pre-Colonial Ilorin, Northern Nigeria. Oman Chapter Of Arabian Journal Of Business And Management Review, [s.l.], v. 3, n. 5, p.43-54, dez. 2013. Al Manhal FZ, LLC. http://dx.doi.org/10.12816/0016452. Disponível em: $<$ https://platform.almanhal.com/Files/2/72675>. Acesso em: 12 nov. 2019.

PARÉS, Luis Nicolau. Africanos Ocidentais. In: SCHWARCZ, Lilia M.; GOMES, Flávio. Dicionário da Escravidão e Liberdade. São Paulo: Companhia das Letras, 2018. p. 77-83.

SAMPAIO, Gabriela dos Reis. Conexões Rio-Bahia: Identidades e dinâmica cultural entre trabalhadores, 1850-1888. Revista Arquivo Nacional, Rio de Janeiro, v. 22, n. 1, p.67-84, jun. $2009 . \quad$ Disponível em: $<$ http://revista.arquivonacional.gov.br/index.php/revistaacervo/article/view/100/100>. Acesso em: 22 fev. 2018.

SIRE, James W.. Toda a diferença do mundo: introdução. In: SIRE, James W.. O universo ao lado: um catálogo básico sobre cosmovisão. 4. ed. São Paulo: Hagnos, 2009. Cap. 1. p. 11-22.

SLENES, Robert. W.. Africanos Centrais. In: SCHWARCZ, Lilia M.; GOMES, Flávio. Dicionário da Escravidão e Liberdade. São Paulo: Companhia das Letras, 2018. p. 64-70.

SOARES, Carlos Eugênio Líbano. Zungú: rumor de muitas vozes. Rio de Janeiro: Arquivo Público do Estado do Rio de Janeiro, 1998.

SOARES, Carlos Eugênio Líbano. Comércio, Nação e Gênero: As Negras Minas Quitandeiras no Rio de Janeiro 1835 - 1900. Revista do Mestrado em História. Vassouras, v. 4, n. 1, p. 55-78, $2001 / 2002$.

SOARES, Cecília Moreira. As Ganhadeiras: Mulher e resistência negra em Salvador no século $X I X$. Afroasia. Salvador, n. 17, p. 57-71. 1996. 
WALDMAN, Mauricio. Africa Tradicional. 2016. Disponível em: $<$ http://mw.pro.br/mw_mw/index.php/materiais-didaticos/8-a-africa-tradicional $>$. Acesso em: 01 ago. 2019.

Recebido 19/02/2020

Aceito em 30/03/2020 